\title{
Engagement characteristics of a friction pad for commercial vehicle clutch system
}

\author{
ARAVIND VADIRAJ \\ Advanced Engineering, Ashok Leyland Technical Centre, Vellivoyalchavadi, \\ Chennai 600103 \\ e-mail: aravindmail@yahoo.com; Aravind.Vadiraj@ashokleyland.com
}

MS received 17 September 2009; revised 28 May 2010; accepted 7 July 2010

\begin{abstract}
A commercially available sintered friction pad is coupled with a standard gray cast iron pressure plate (FG 250 grade) and tested in a clutch dynamometer for understanding the engagement characteristics and thereby predicting the useful life in number of engagements. Results show that sintered friction pad has a very stable range of friction coefficient $(0.43-0.61)$ even after 5000 engagement cycles. The torque transmitted ranges from 350 to $400 \mathrm{~N}$ during one engagement cycle. The energy dissipation and mass loss of friction materials linearly increases with increasing sliding distance. A correlation is derived based on energy dissipation and mass loss in terms of total number of useful or available engagements before replacement or repair of friction pad or clutch pressure plate. Both the pressure plate and clutch disc with the sintered friction pad was tested in a 49 tons load capacity vehicle on a test track. Both sintered friction pad and pressure plate showed scoring marks along the sliding direction. Friction pad showed dense cracks along the top edge. Microscopic features of worn sintered friction pads show silica particle providing the required wear resistance for the pads. Pressure plate showed transfer layer of oxides and carbon with less scoring marks due to short duration vehicle level trials.
\end{abstract}

Keywords. Clutch; friction; wear; failure analysis.

\section{Introduction}

Clutch is a torque transmitting mechanical device in an automobile. This is designed according to the load carrying capacity of an automobile. There are two main types of clutches: Wet clutch and dry clutch. Dry clutches are commonly used for haulage and passenger vehicles. The main components of the clutch systems are: (i) pressure plate, (ii) clutch disc, (iii) flywheel (includes pilot bearing or bushing), (iv) release bearing and (v) release system (hydraulic, mechanical or cable).

The clutch system (clutch disc and cover assembly) of a typical heavy commercial vehicle is shown in figure 1 . The clutch disc has friction facing buttons riveted radially around a central splined hub. The buttons are fitted both on front and back sides of the support plate facing 


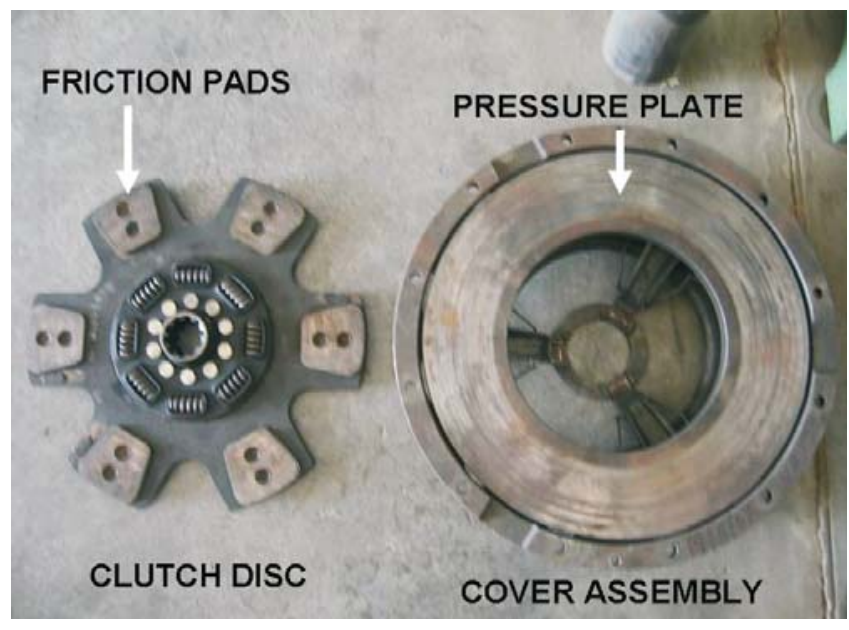

Figure 1. Clutch disc and cover assembly of a heavy commercial vehicle.

pressure plate towards the transmission and face plate mounted on the flywheel both made of gray cast iron. They are currently manufactured with organic and cerametallic (ceramic particulates in a metal matrix) based friction facing for passenger or haulage commercial vehicles. Friction facing couples with flywheel on the engine side and pressure plate towards the transmission side to arrest the torque.

Cover assembly consisting of a pressure plate $(\sim 25 \mathrm{~mm}$ thick for heavy load carrying commercial vehicles) fitted within a cover assembly backed by clamp springs for applying engagement pressure (figure 1). The cover assembly consists of pressure plate operated by coil or diaphragm springs from behind actuated by 3 or 4 finger arrangements through antirattle springs. The release bearings operate the finger movement for engaging or disengaging through clutch operating lever connected to either mechanical actuation or hydraulic actuation ending with a clutch pedal. This entire assembly is fitted into the flywheel and clutch disc is placed between the pressure plate and flywheel. The engine power is transmitted through frictional engagement of clutch disc, pressure plate and flywheel.

The scope of this work is to understand the engagement characteristics and failure analysis of a commercial vehicle clutch system. A brief study on friction pad and pressure plate material is followed by study on engagement characteristics and failure analysis of materials tested in a 49 ton commercial vehicle on a test track.

\section{Materials}

\subsection{Sintered friction pads}

Friction pads are manufactured by sintering a blend of powders consisting of heat absorption materials along with friction generating and lubricating materials. The powders are blended in optimized proportions and compacted to form a solid flat button of predetermined shape. Then the button is sintered on a copper plated steel backing plate under determined pressure to form a friction pad. They are highly durable with harsher engagement characteristics compared to organic linings. The quality of materials used along with the sintering parameters play an important role in providing the required performance (Aleksandrova et al 1972). Particulate reinforcement gives the necessary wear resistance for the sintered matrix (Mustafa Boz \& Adem Kurt 2007). 


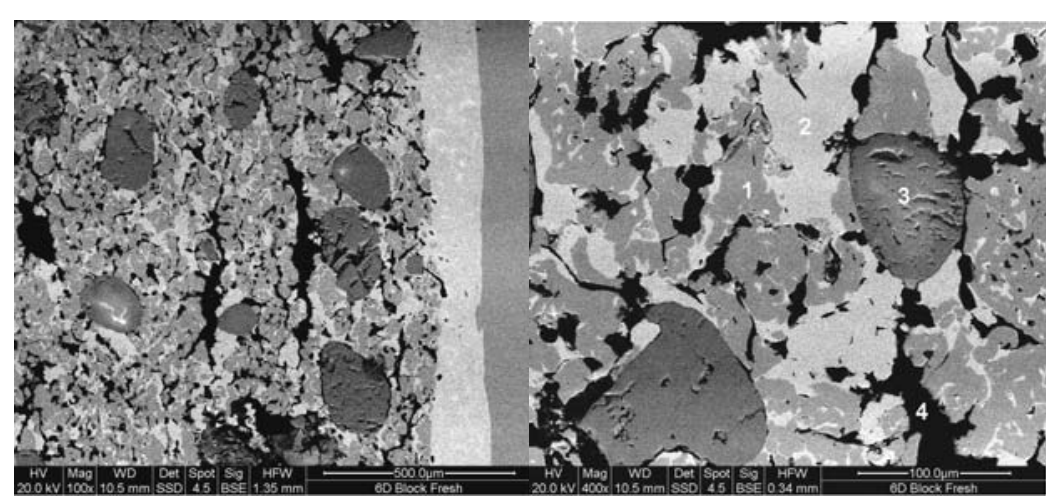

(a)

(b)

Figure 2. Microstructure of sintered material showing sintered compact on copper coated (white layer, figure 2a) steel backing plate (Gray layer, figure 2a). Higher magnification micrograph of the compact is presented in figure $2 b$.

They offer the following advantages (Peter 1998) (i) high temperature resistance up to $500^{\circ} \mathrm{C}$, (ii) good wear resistance, and (iii) stable range of friction $(0.4$ to 0.6 ). These buttons are also used commonly in disc brake systems. They are most popularly used in heavy duty vehicles operating on rugged terrains carrying heavy loads. They give good service life for heavy commercial vehicles with capacity of 22 tons and above. The buttons vary in area, thickness, and composition according to different applications. Friction pads with larger area and higher thickness will wear slowly, last longer but costlier.

The microstructure of sintered compact on a copper coated steel plate is as shown in figure 2. The gray particles are iron which makes up the large part of the pad material. The particulates are nicely blended with uniform distribution across the section. Silica particulates are observed as chunky circular or oval sized black sporadically distributed mass across the cross section. They provide the necessary wear resistance for the friction pad by forming a barrier during sliding.

Table 1 shows the characteristics of microconstituents of cerametallic friction facing. Tin bronze in conjunction with iron produces the required friction. The mechanical and wear properties of bronze increases with increase in tin. The best tribological properties were obtained with $15 \%$ tin (Ghorbani et al 2005). Graphite acts as dry lubricant to prevent excessive wear and iron is the main component for generating friction (Peter 1998; Jorge et al 2005).

Table 1. Characterization of microconstituents of a typical cerametallic friction facing.

\begin{tabular}{|c|c|c|c|}
\hline $\begin{array}{l}\text { Index } \\
\text { (See figure 2b) }\end{array}$ & Constituents & Volume(\%) & Avg. particle size $(\mu \mathrm{m})$ \\
\hline 1 & Steel & $60-70$ & $30-100$ \\
\hline 2 & Tin Bronze & $10-15$ & $35-110$ \\
\hline 3 & $\mathrm{SiO}_{2}$ & $8-10$ & $80-250$ \\
\hline 4 & Graphite & $5-7$ & $50-500$ \\
\hline
\end{tabular}


Graphite and silica is fixed at optimum volume for the required performance. Higher graphite content decreases the composite hardness as well as friction and wear of the pad (Ghorbani et al 2005). Silica content above the optimum level may reduce the life of the mating part.

\subsection{Pressure plate}

Pressure plates are generally made of gray cast iron with type-A graphite distribution having good wear and heat transport properties. The required friction for clutching is generated due to metallurgical compatibility between the predominating iron based matrix in both the friction pad and gray cast iron pressure plate. The required properties can be achieved by controlling chemical composition, cooling rate and heat treatment. Pressure plates for heavy duty commercial vehicles must possess properties much superior to conventional grades of cast iron since they undergo arduous conditions during service. For such applications, the conventional grades of cast iron are alloyed with determined additions of elements like $\mathrm{Ni}$, $\mathrm{Mo}, \mathrm{Cu}$ or $\mathrm{Cr}$ which enhances mechanical and tribological properties to withstand the abusive service conditions.

In order to obtain a reasonable functional life, the quality control department based on in-house and field experience has come up with some specific properties on pressure plate as follows: (i) Hardness (210 to $260 \mathrm{BHN}$ ), (ii) Microstructure (min 15\% graphite with fully pearlitic matrix and free ferrite less than 5\%), (iii) Tensile strength (min $250 \mathrm{MPa}$ ), (iv) Good wear resistance, (v) High heat conductivity, (vi) High burst strength (to withstand the burst failure at 10,000 r.p.m for $1 \mathrm{~min}$ ), (vii) Good machinability (48\% for ASTM class 40 gray irons (300 MPa UTS) relative to 1212 carbon steel (100\% machinable)).

\section{Engagement characteristics}

\subsection{Experimental details}

Commercially available sintered friction pads and pressure plate (gray cast iron FG 250 grade) were tested to investigate the performance in an inertia type dynamometer rig according to the conditions given in table 2. Standard pin-on-disc test rigs (ASTM G99-E05) cannot exactly simulate the wear and sliding speeds of clutch engagement and disengagement like dynamometers (Ost et al 2001). Therefore, pin-on-disc test results are generally taken as a qualitative indication for assessment of tribological behaviour of representative clutch friction materials (Khamlichi et al 2008).

The pressure plate used was $270 \mathrm{~mm}$ in diameter. A clamp load of almost $7 \mathrm{kN}$ simulates the original service condition load in a 16 tons capacity passenger vehicle. The engagement occurs when rotation speed attains 1350 r.p.m. Friction pad is forced against the pressure plate

Table 2. Test conditions.

\begin{tabular}{lc}
\hline Clamping load & $6940 \mathrm{~N}$ \\
Specific pressure (on full engagement) & $0.675 \mathrm{MPa}$ \\
No. of total engagements & 5000 \\
Pressure plate & FG 250 \\
Max r.p.m (revolutions per minute per engagement) & 1350 \\
\hline
\end{tabular}


with a gradually increasing normal load against a rotating pressure plate until the rotation completely stops.

The test was conducted for 5000 engagements at 3 engagements per minute. Friction force, coefficient of friction for a specific sliding distance per engagement is recorded directly from the dynamometer. Energy dissipated is calculated from the following relation:

Energy dissipation $=($ frictional force $) \times($ sliding distance $)$.

Energy dissipated and wear loss was calculated after every 250 engagements. The torque and power developed was calculated from the following relations:

Torque $(\mathrm{Nm})=($ friction force $) \times($ effective friction radius $)$.

Power $(\mathrm{kW})=($ Torque $\times$ R.P.M $) / 9549$.

\subsection{Life prediction}

The test results obtained are shown in table 3 . The PV (pressure $\times$ velocity) value of 9.45 is quite high to cause seizure during dry sliding. An increase in velocity at high enough applied pressure under dry sliding conditions generates very high friction induced temperature at the contact to cause localized welding or seizure. Every contact pairs generally has some limit on PV values specified for sliding under dry conditions. In some cases like on mild steel, a value of 10 is specified to be the limit. In this case, we observe that although the sliding velocity is very high $(14 \mathrm{~m} / \mathrm{s}$ see table 3$)$, the contact pressure is very small $(0.625 \mathrm{MPa}$ see table 2). Although this brings the value of PV close to 10, the pressure component has to predominate to cause any seizure. Moreover, the currently used friction materials which is a composite of iron, bronze, silica and graphite is paired with gray cast iron having very high thermal conductivity due to graphite flakes. So the contact pairs are not so metallurgically compatible and the heat also can be dissipated very fast from the contact by the gray cast iron. However, the velocity component here predominates more than specific pressure applied and hence frictional engagement takes place without seizures. The volumetric wear coefficient of friction material is almost same as pressure plate (table 3 ).

The pressure plate rotation is fully arrested within $1 \cdot 1$ seconds on full engagement pressure of $0.675 \mathrm{MPa}$ as shown in figure 3 in one engagement cycle. The zone before the specific pressure attains steady value $(0.675 \mathrm{MPa})$ is called modulation zone. Coefficient of friction varies from 0.43 to 0.61 after 5000 engagement cycles.

The torque varies between 350 and $400 \mathrm{Nm}$ during one engagement while the output power steadily decreases with increasing energy dissipation as observed in figure 4 . The torque

Table 3. Test results.

\begin{tabular}{lc}
\hline Torque @ 1360 r.p.m & $402.5 \mathrm{Nm}$ \\
Sliding speed & $14 \mathrm{~m} / \mathrm{s}$ \\
P × V(pressure × velocity) & 9.45 \\
Energy dissipation (per engagement) & $62 \mathrm{~kJ}$ \\
Specific Energy dissipated (per engagement) & $4.025 \mathrm{KJ} / \mathrm{m}$ \\
Total Energy dissipated (after 5000 engagements) & $310 \mathrm{MJ}$ \\
Specific power generated per unit energy dissipated & $1.7 \mathrm{~W} / \mathrm{J}$ \\
Total power output & $56.83 \mathrm{~kW}$ \\
Volumetric wear coefficient of friction pad & $1.71 \times 10^{-9} \mathrm{~mm}^{3} / \mathrm{Nm}$ \\
Volumetric wear coefficient of pressure plate & $1.70 \times 10^{-9} \mathrm{~mm}^{3} / \mathrm{Nm}$ \\
\hline
\end{tabular}




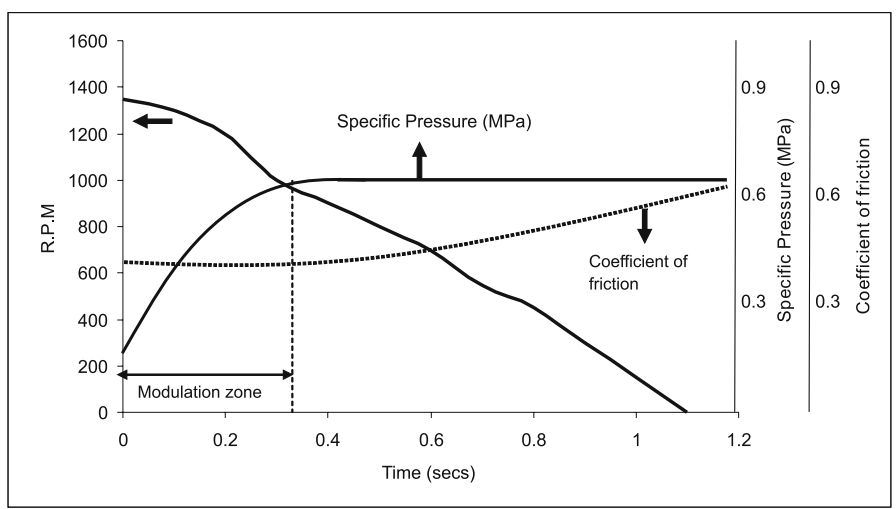

Figure 3. Variation of applied pressure, coefficient friction and rotational speed with time.

variation is directly related to the friction force during engagement. The energy dissipation increases steadily with increase in sliding distance as shown in figure 5. One engagement dissipates $62 \mathrm{~J}$ of energy.

There is a linear average cumulative mass loss with continuous sliding as shown in figure 6 . It can be noted from figure 6 that two mass loss is progressing equally for both pressure plate as well as friction facing since both are iron based material. Friction facing and pressure plate has something in common. Friction facing has graphite along with wear resistant particles like silica embedded in it while pressure plate material also has graphite flakes with hard wear resistant carbides in it. Therefore, both have pertinent features qualifying them for friction and wear applications. Hard particulates acts as barrier to prevent wear loss of material while graphite acts as dry lubrication to reduce adhesive and abrasive wear of material by forming thin transfer layer of carbon at the interface. The presence of graphite beyond a threshold limit predominates to significantly reduce wear losses in the systems (Ost et al 2001).

Based on the graphs shown in figures 4 to 6 , correlations based on trend line were observed with respect to torque, energy dissipation during engagement, mass loss of friction

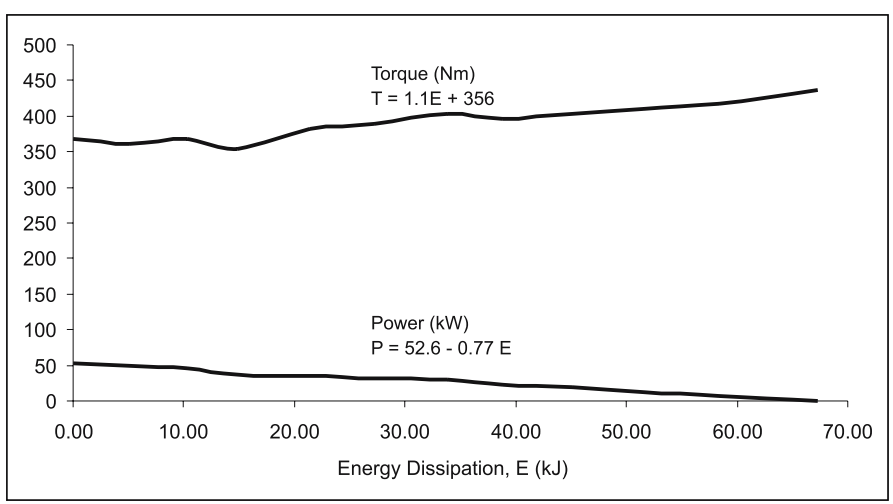

Figure 4. Torque and power generated during frictional energy dissipation in one engagement cycle. 


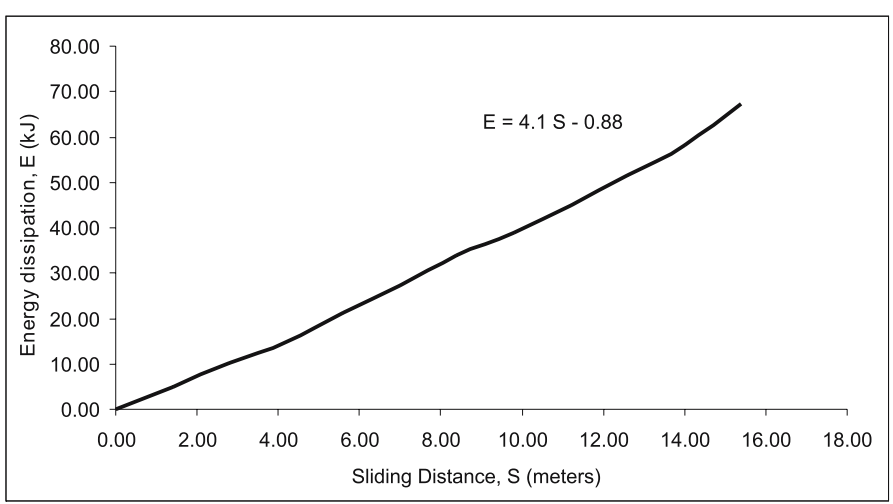

Figure 5. Energy dissipated with sliding distance during single engagement.

pads/pressure plates. The correlations are as follows:

$$
\begin{gathered}
T=1 \cdot 1 E+356, \\
P=52 \cdot 6-0.77 E, \\
E=4 \cdot 1 S-0 \cdot 88, \\
M=\left[9 \times 10^{-5}\right] S,
\end{gathered}
$$

where $T=$ Torque $(\mathrm{Nm}), P=$ Power $(\mathrm{kW}), E=$ Energy dissipated per engagement $(\mathrm{kJ})$, $S=$ Sliding distance (meters), $M=$ Mass loss (gms).

The torque and power generated during one engagement cycle is computed by equations ( 1 and 2). The power transmitted gradually decreases with the decrease in rotation speed during engagement as shown in equation (2). Frictional power dissipation is one of the important variables to assess the critical wear characteristics of friction materials or to compare different friction materials (Roberto et al 2009). It is observed from equation (3) that energy dissipated before clutch engagement is almost four times the sliding distance.

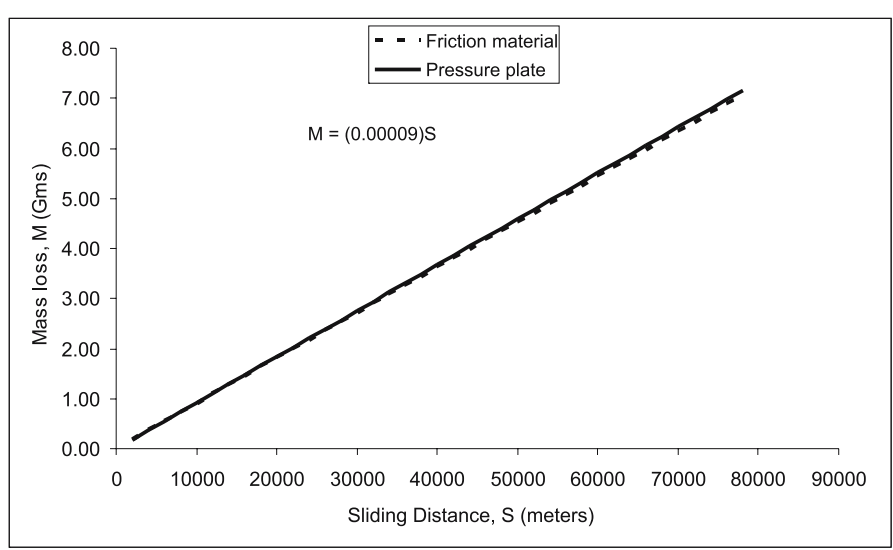

Figure 6. Trend line showing increase in mass loss with increase in sliding distance. 
Mass loss of friction material or pressure plate at any time is related to sliding distance as shown in equation (4).

The above correlation only pertains to the friction pad and pressure plate pairs currently tested. The parameters derived may vary for different materials that are used for pressure plate and friction facing. In this regard, a general correlation may be derived equating (3) and (4) for same sliding distance.

$$
E / k_{1}=M / k_{2},
$$

where $k_{1}$ and $k_{2}$ are slopes that can be obtained from trend lines in graphs $5 \& 6$ respectively. These values may be different for different materials. Alternatively, equation (5) can be translated to include dimensional, material and engagement parameters to obtain a correlation in terms of total number of engagements of friction pad or pressure plate material:

$$
N_{\text {Eng }}=\left[\frac{k_{1}}{k_{2}}\right]\left[\frac{A_{f} t_{c} \rho}{\mu N S_{E}}\right],
$$

where $N_{\text {Eng }}=$ Life of pressure plate or friction pad in total number of engagement cycles before replacement or repair, $k_{1}=$ slope of energy dissipation $(\mathrm{Nm}) \mathrm{Vs}$ sliding distance $(\mathrm{m})$ plot (figure 6), $k_{2}=$ slope of Mass loss (g) Vs Sliding distance (m) plot for pressure plate/flywheel or friction material (figure 7$), A_{f}=$ Contact area $\left(\mathrm{mm}^{2}\right), t_{c}=$ Threshold worn depth/thickness of pressure plate or friction pad before replacement or repair $(\mathrm{mm})$, $\rho=$ Density of the material $\left(\mathrm{g} / \mathrm{mm}^{3}\right), \mu=$ Average coefficient of friction, $N=$ Clutch clamping pressure $(\mathrm{kN}), S_{E}=$ Sliding distance per engagement $(\mathrm{m})$.

The useful life of clutch friction pads or pressure plate in terms of number of engagements $\left(N_{\text {Eng }}\right)$ can be obtained with small number of engagements from equation (6) instead of continuing experiment till failure which would be more time-consuming and expensive. The values of $k_{1}$ and $k_{2}$, which are specific to a particular pair of friction pad and pressure plate, should be obtained from dynamometer test simulating the original service conditions.

Threshold thickness $\left(t_{c}\right)$ of friction pad is the useful material thickness available before it is replaced. The friction pad is riveted along the periphery of the clutch disc (figure 1). Therefore, the material loss can occur until the rivet head is reached. For pressure plates, the engagement of friction pad creates worn out grooves. The threshold depth in case of heavy commercial vehicles is normally 0.5 to $1 \mathrm{~mm}$ before they are resurfaced or replaced. Beyond threshold wear depth, the clutching will cause excessive slipping and rise in interfacial temperature. The critical worn depth is identified based on the driver's inability to drive the vehicle even in full throttle. The other parameters required in equation (6) are either known material/dimensional parameters or obtained directly from dynamometer.

\section{Wear analysis of friction pad}

The clutch disc with the cerametallic friction facing was fitted into a 49 tons load carrying capacity vehicle and sent for a short duration test track trials to understand the performance. The clutch clamping load was $19 \mathrm{kN}$. Worn cerametallic friction facing is shown in figure 7. Crack networks were observed along the friction surface perpendicular to the sliding direction. The crack distribution is denser on the outward region of the button as sliding distances are higher compared to inner circle. For the same clamp load, the sliding speed is higher at the outer periphery. The differences in the thermal expansion coefficient between the particles 


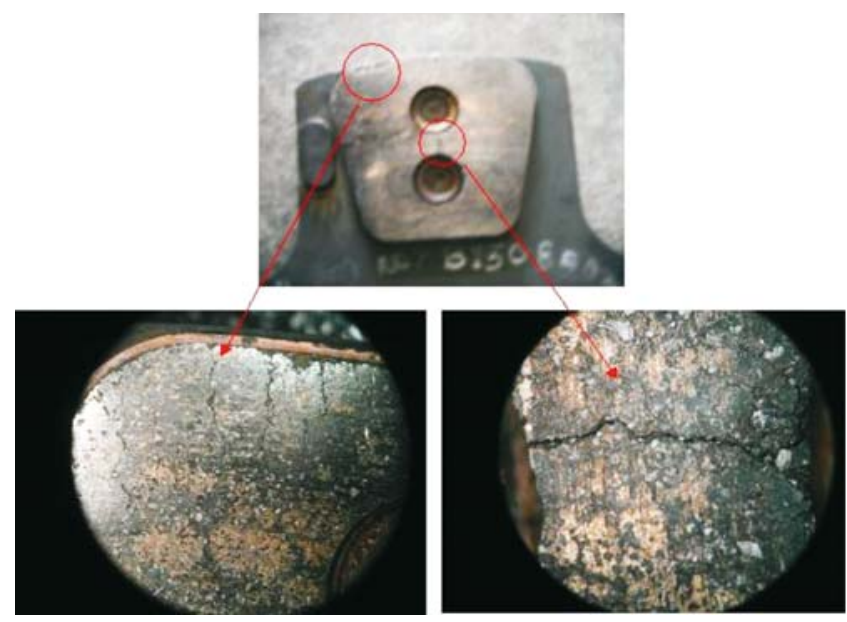

Figure 7. Cracks on field failed cerametallic button.

can also disintegrate the compact along the particle interface. Closer observation also reveals silica particulates within wear tracks (figure 8). The graphite particulates have been either knocked off or settled with iron oxide debris within the cavity. Particulate transfer is also clearly observed along with the friction track. The blackened region is mostly compacted mixtures of oxide of iron and graphite. The distribution also varies for different regions due to non-uniform contact. This is observed from the contrasting dark and light regions in figure 7. The oxide formation is influenced from high frictional temperature and will be from the removal of metal from both the mating components. The oxides so formed will be removed as debris during subsequent engagements. The material with predominant volume fraction of iron particles would normally dominate in adhesive wear due to metallurgical compatibility between friction facing and gray cast iron pressure plates.

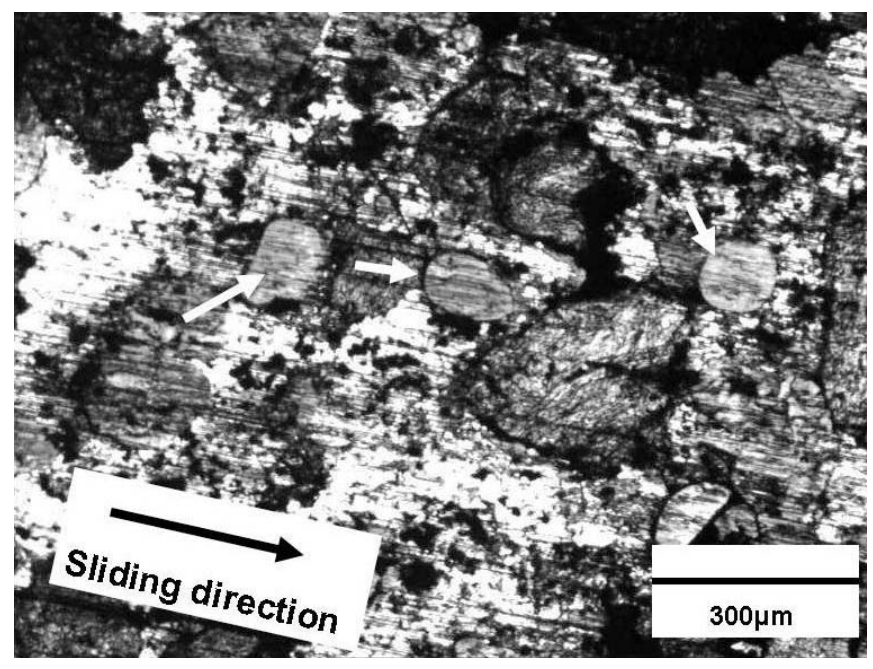

Figure 8. Silica particles (white arrows) within the cerametallic friction facing matrix. 


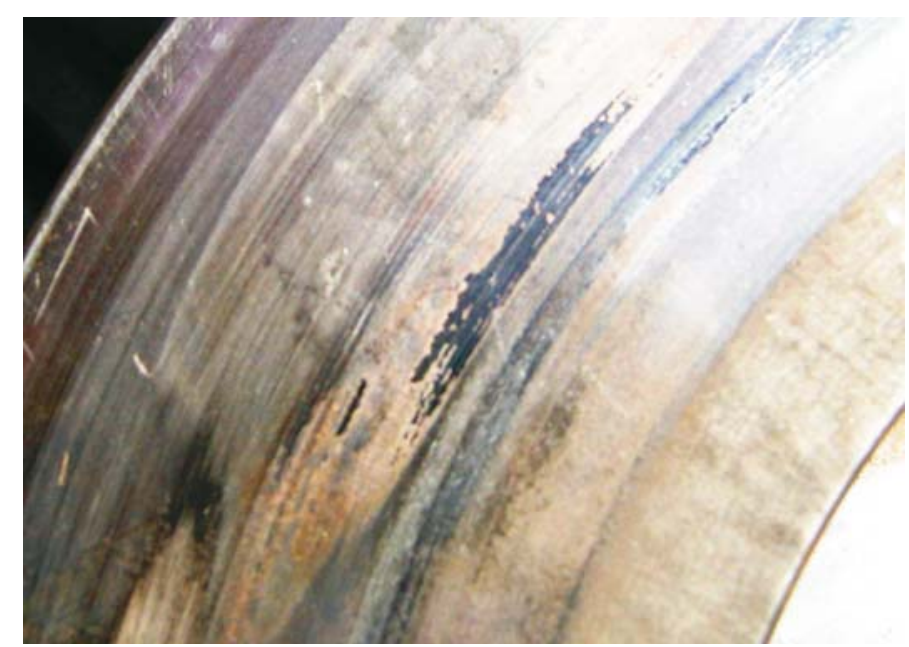

Figure 9. Wear tracks on pressure plate.

\section{Wear analysis of pressure plate}

The wear tracks generated on the pressure plate after test track trails as shown in figure 9. The depth of worn area is very much less compared to field failures since the trials were made for short period. The depth gradually increases during service until it fails to provide the clutch engagement. Pressure plates are normally resurfaced by grinding as and when it develops such grooves. It is only replaced when there is irrecoverable distortion. Serviced pressure plates surface are usually composed of transfer layers of carbon and iron oxide mixtures. The dark patches of such transfer layers are evident in figure 9. The carbon can come from both the pressure plate (gray cast iron with flake graphite) and the friction pad (having 5\% graphite particles). The presence of iron oxide as tribolayer can sometimes reduce wear severity depending upon the particle size (Kato Hirotaka 2003). Therefore, both iron oxide and carbon can help reduce wear severity while maintaining the required friction for clutching. The difference in shades on the worn surface of the pressure plate is due to nonuniform contact of the friction pad during sliding. Perfect conformity in contact does not happen during clutch engagement leading to non-uniform tribolayer deposition.

\section{Conclusions}

A commercially available sintered friction pad engaged against gray cast iron (FG 250 grade) pressure plate produces stable range of friction $(0.43-0.61)$ even after 5000 engagements. Full engagement occurs within 1.2 seconds from the rotation speed of 1350 r.p.m. The torque level transmitted, which depends on the frictional force during engagements, varied between 350 and $400 \mathrm{Nm}$. The energy dissipated and mass loss show a linear trend with sliding distance. The energy dissipated in one engagement is almost four times the sliding distance.

A correlation based on energy dissipated during clutch engagement and wear loss of friction $\mathrm{pad} /$ pressure plate due to frictional engagement has been derived to obtain the useful life of friction pad or pressure plate material in terms of number of engagements. This correlation 
can provide the life of clutch friction materials in terms of number of engagements within small number of engagement cycles.

Sintered friction pad showed dense crack networks around the periphery due to thermal cycling during engagement and disengagement cycles. Microscopic features show silica particle providing the wear resistance for the pads. Slight scoring marks were observed in the pressure plate with little transfer layer of carbon and iron oxide mixture.

\section{References}

Aleksandrova A B, Kryachek V M, Levit G B, Rozenshtein D G, Fedorchenko I M, Prikhod"ko L P, Izvekov G V 1972 Effect of sintering conditions on the structure and frictional and wear properties of powder metallurgy friction disks. Powder Metallurgy and Metal Ceramics 11(10): 831-834

Ghorbani M, Mazaheri M and Afshar A 2005 Wear and friction characteristics of electrodeposited graphite-bronze composite coatings. Surface and Coatings Technology 190(1): 32-38

Jorge Alberto, Lewis Esswein Junior, Fabiano Edovirges Arrieche, Lírio Schaeffer 2008 Analysis of Wear in Organic and Sintered Friction Materials Used in Small Wind Energy Converters. Materials Research 11(3): 269-273

Kato Hirotaka 2003 Severe-mild wear transition by supply of oxide particles on sliding surface. International Conference on Wear of Materials 255: 426-429

Khamlichi A, Bezzazi M, Jabbouri A, Reis P, Davim J P 2008 Optimizing friction behaviour of clutch facings using pin-on-disk test. Inter. J. Physical Sci. 3(2): 65-70

Mustafa Boz, Adem Kurt 2007 The effect of $\mathrm{Al}_{2} \mathrm{O}_{3}$ on the friction performance of automotive brake friction materials. Tribology International 40(7): 1161-1169

Ost W, De Baets P, Degrieck J 2001 The tribological behaviour of paper friction plates for wet clutch application investigated on SAE II and pin-on-disk test rigs. Wear 249(5-6): 361-371

Peter W Lee 1998 Friction Powder Metallurgy Materials, Powder Metal Technologies and Applications. ASM Handbook, 7: 823-850

Roberto C Dante, Francesco Vannucci, Pietro Durando, Enzo Galetto, Czeslaw K Kajdas 2009 Relationship between wear of friction materials and dissipated power density. Tribology International 42(6): 958-963 